\title{
Topography and Morphology of a Hydrogel Enriched with Allantoin for Biomedical Purposes
}

Rosa A Saucedo-Acuña ${ }^{1,2}$, María L. Barrios-de la $\mathrm{O}^{1}$, Karla L. Tovar-Carrillo ${ }^{1,2}$, Elsa G. OrdoñezCasanova $^{3}$, and Carlos Rodríguez-Rodríguez ${ }^{4}$

1. Instituto de Ciencias Biomédicas - Universidad Autónoma de Ciudad Juárez. Anillo Pronaf s/n. Zona Pronaf Cd. Juárez, México.

2. Grupo Evelsa. Hermanos Escobar 6150-2 Parque Ind. Omega, Cd. Juárez, México.

3. Instituto de Ingeniería y Tecnología - Universidad Autónoma de Ciudad Juárez. Av. Del Charro. 450 Col. Partido Romero. Cd. Juárez, México.

4. Universidad Tecnológica de Ciudad Juárez. Ave. Universidad Tecnológica No. 3051, Lote Bravo II Cd. Juárez, México.

The intention to obtain a biodegradable hydrogel enriched with allantoin is to conform a medium of distribution for this natural extract. In this case allantoin was distributed in two layers. One layer to be released immediately into the area of interest and in a second layer for prolonged action. It is known antibacterial and regeneration properties by allantoin, but until today we can only understand antibacterial mechanism, while its role of this extract in the regeneration process still not understood. [1 - 7]

SEM images of pectin hydrogel enriched with allantoin show a homogeneous distribution in both layers, but more important we could verify a porous structure in the allanotin particle not reported before. This kind of structure could contribute the regeneration properties reported by allanotin, because cells and growing factors could penetrate allantoin as used it as a conjunctive tissue like other porous materials for support matrix do it.

A JEOL microscope model JSM-6010PLUS/LA was used for the analysis. Samples where dried and cut $5 \mathrm{X} 5 \mathrm{~mm}$ and the images were taken at low vacuum and 5kV. Figure 1 shows a transversal section where a layer rich in allantoin with approximately $291 \mu \mathrm{m}$ was observed. Figure 2 shows a longitudinal section of this layer with a particle size distribution between 10 to $50 \mu \mathrm{m}$. The roughness observed is an ideal characteristic of a material for tissue regeneration propose.

To obtain a closer image of the natural extract we cover the sample with gold. Moreover, in Figure 3 we could find an unexpected porous structure of allantoin. We observed a nano and microporous size distribution. For this reason, we suggest that allantoin structure could allow penetration of grow factors and cells to promote cell adhesion and tissue regeneration for biomedical proposes.

References:

[1] V. Vagenende et al, J. of Chromatography A 1310 (2013), p. 15.

[2] N. Kus, S. Haman Bayarı, and R. Fausto. Tetrahedron 65 (2009), p. 9719.

[3] J. R. Walker et al, J. Mol. Biol 358 (2006), p. 810.

[4] G. Svetlichny et al, J. of Drug Delivery Sci. and Tech. 40 (2017), p. 59.

[5] R. Rennó Bragaa, et al, Spectrochimica Acta Part A 91 (2012), p. 389.

[6] H. Karagoz et al, Burns 35 (2009), p. 1097.

[7] I. Florentino et al, J. of Ethnopharmacology 186 (2016), p. 298. 


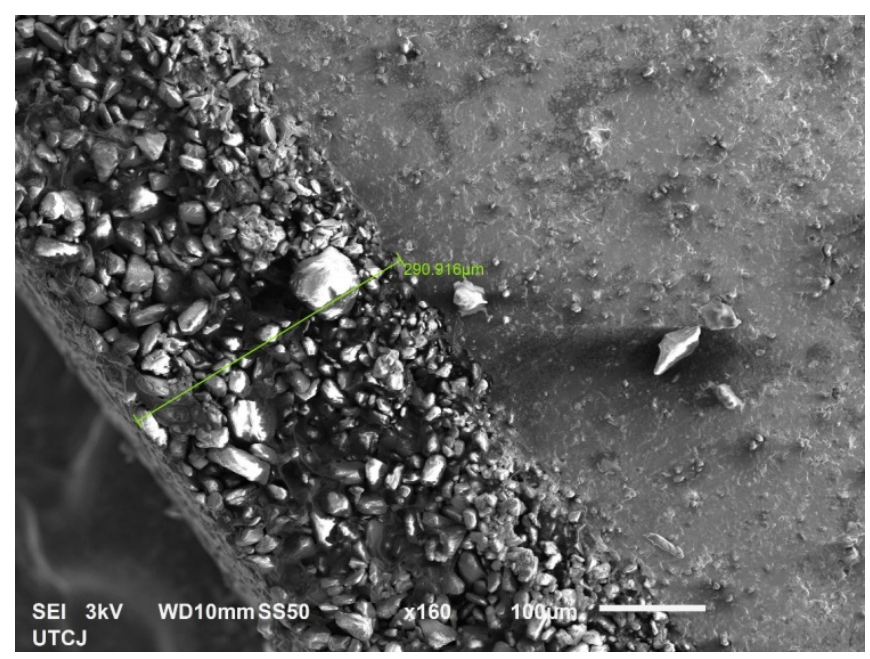

Figure 1. SEM image of transversal section of hidrogel enriched with allantoin.

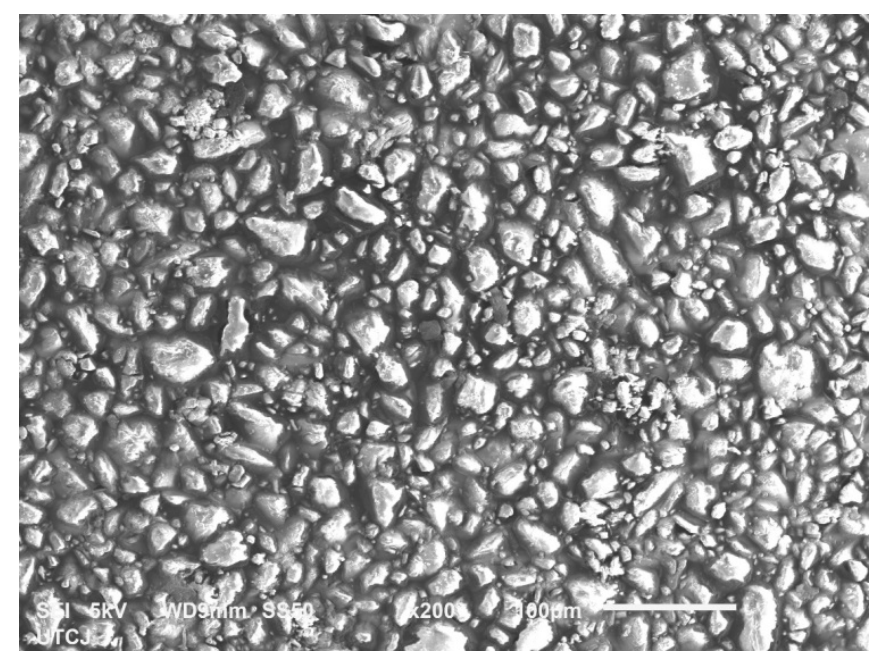

Figure 2. SEM image of longitudinal section of layer riches in allantoin.

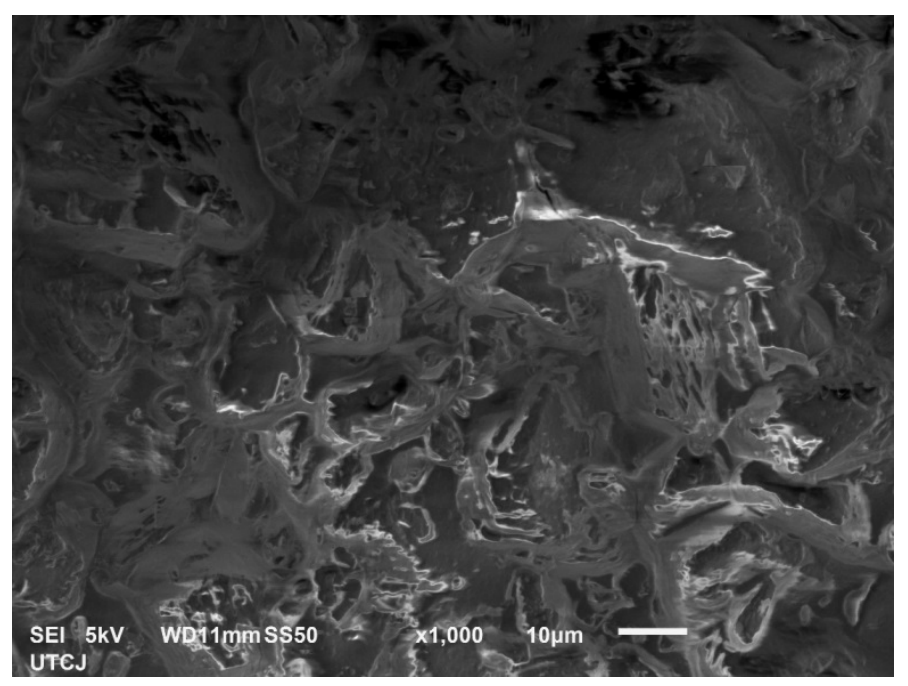

Figure 3. SEM Image of a particle of allantoin. 